\title{
The Role of Artemia spp (Branchiopoda: Artemiidae) as Intermediate Hosts for Avian Cestodes
}

\author{
Rolf Karl Schuster* \\ Central Veterinary Research Laboratory Dubai, UAE \\ *Corresponding author: Rolf Karl Schuster Central Veterinary Research Laboratory Dubai, PO Box 597, UAE
}

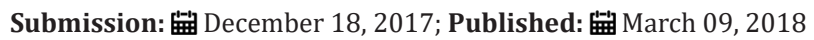

\begin{abstract}
Brine shrimps of the genus Artemia can tolerate hyper saline aquatic environments and thus, are able to occupy ecological niches. These brachiopod crustaceans play an important role as food source for flamingos and other waders and act as intermediate hosts for a variety of cestodes. Comparison of scolex structures of adult tapeworms with those of the cysticercoids in Artemia spp gave evidence that brine shrimps act as intermediate hosts for Aploparaksis parafilum, Brachiopodataenia gvozdev, Confluaria podicipina, Fimbriaroides tadornae, Flamingolepis caroli, F. flamingo, F. liguloides, F. tengizi, Hymenolepis californicus, Wardium fusca and W. stellorae of the Hymenolepididae family, Anomolepis averini, Anomotaenia tringae and A. microphallus of the Dilepididae family and Gynandotaenia stammeri and Gynandrotaenia spp. a so far undetermined further species of this genus of the Progynotaeniidae family.
\end{abstract}

Keywords: Artemia; Brachiopoda; Cysticercoids; Hymenolepididae; Dilepididae; Progyotaeniidae

\section{Introduction}

Brine shrimps or Artemia is a phylogenetically old genus of aquatic crustaceans contains of sibling species and super species defined by the criterion of reproductive isolation. The species inventory of the genus is disputed but according to Asem et al. [1] it consists of Artemia salina, A. monica, A. urmiana, A. franciscana, A. sinica, A. tibetiana and parthenogenetic populations called $A$. parthenogenetica. Brine shrimps can tolerate saline (2.5\%) to hypersaline $(25 \%)$ waters with an optimum range of $6-10 \%$ salinity and occur world-wide in inland salt waters and thus, occupy ecological niches that protect them from predators such as fish. Under normal conditions female brine shrimps are ovo-viviparous and naupilus larvae usually hatch immediately after placement of eggs while unfavorable conditions (low oxygen, rising temperatures, desiccation of pools) led to the production of floating, thick shelled, metabolically inactive brown cysts that can survive for up to two years in dry conditions and hatch when hydrated under optimal conditions [2]. Naupuli of brine shrimps are among the most widely used live diet in the larviculture of fish and shellfish and over 2000 metric tons of dry Artemia cysts are marked world-wide [3]. Brine shrimps are also a major compound in the diet of flamingos and a number of waders occurring in subsequent habitats and during evolution a relationship between these birds, their cestodes and brine shrimps acting as intermediate hosts has been established.

\section{Cestodes using brine shrimps as intermediate hosts}

Hymenolepis californicus was the first species that was detected

in its larval stage in brine shrimps of Mono lake and salt pools near Chula Vista in California. To establish the relationship of this cestode larvae with the adult tapeworm Young [4] fed laboratory hatched California gulls and proved the identity of cysticercoids and adult cestodes grown in the gulls. Starting in the $1970^{\text {th }}$, scientists of the Zoological Institute in Almaty started ecological studies in the in the lake Tengiz in the Tselinograd district of northern Kazakhstan. This undrained lake is fed by the river Nura and occupies a territory of $1,950 \mathrm{~km}^{2}$. Tengiz is the largest saline lake in Kazakhstan and its shore and surroundings of the Korgalzhin National Park is home to the most northern population of greater flamingos and more than 300 other birds. The occurrence of $A$. salina on a massive scale in the Tengiz Lake gave reason to investigate its role as possible intermediate hosts for avian cestodes since eight different species of tapeworms were found in greater flamingos originating from that place [5]. Out of 36.500 brine shrimps collected between July and October $19712.235(=6.1 \%)$ specimens were infected with 10 different cysticercoids. Amongst them were three representatives of the family Hymenolepididae: Flamingolepis dolgushini, F. tengizi and Aploparaksis parafilum in prevalence of $3.0 \%, 0.13 \%$, and $0.033 \%$ respectively [6]. 
The examination of the helminthofauna of the shelduck led to the description of a new hymenolepidid cestode, Fimbriaroides tadornae. Eggs of this tapeworm were fed to A. salina and the development of the cysticercoid was monitored. Under conditions of $6.5 \%$ salinity and a constant temperature of $22^{\circ} \mathrm{C}$ the development Were completed at day 12 to 13 after infection. Out of 140 brine shrimps used $76(=54.3 \%)$ became infected and harbored up to13 cysticercoids. No information on the natural infection of $A$. salina in the lake Tegiz was given [7]. Cysticercoids of Anomolepis averini was found in A. salina in high prevalence of $5.3-9.1 \%$ in the bays of the Tengiz lake while in collecting places that were located at a far distance from the shore prevalence was much lower and reached only $0.4-0.86 \%$. Branchinella spinosa, another brachipod harbored also Anopolepis cysticercoids but in low prevalence of $0.22 \%$ [8]. The adult tapeworm of this dilepidid cestode was found in numbers of 1-15 in intestines of the red necked phalaropes in a prevalence of $13.7 \%$. Gynandotaenia stammeri of the Progynotaeniidae family was present in $0.04 \%$ of examined shrimps [9]. The presence of G. stammeri in brine shrimps in the French Carmague was also mentioned by Gabrion \& Mac Donald [10]. Confluaria podicipina, a hymenolepidid cestode originally described from grebes northern America was also detected in black necked, great crested and in red-necked grebes in Kazakhstan [11-13].

Larval stages with eight aploparaksoid hooks on the scolex matching in size and shape with those found of $C$. podicipina in grebes were present in $A$. salina from Lake Tengiz in a prevalence of $0.05-0.35 \%$ [14]. Further research was dedicated to hymenolepidid cestodes of the genus Wardium that parasites the intestines of gulls and subsequent cysticercoids that were seen in A. salina originating from Tengiz lake. These were Wardium stellorae [15] and W. fusca [16]. Among the Wardium species from gulls of the lake Tengiz was a so far undescribed new species, $W$. gvozdevi that occurred in a high prevalence in slender billed gulls. Experimental infections of A. salina carried out at $22-24{ }^{\circ} \mathrm{C}$ showed that the development of cysticercoids of W. gvozdevi is completed within 12-15 days [17]. A cysticercoid scolex structures of which matched with those of the cestode Wardium manubriatum of the slender billed gull was detected in a single fairy shrimp (Branchinella spinosa) collected in the lake Tegiz [18]. The cysticercoid of Eurycestus avoceti, a dilepidid cestode of the avocet was originally described from Artemia sp. from Camargue, a wetland in southern France in a paper by Gabrion \& MacDonald [10]. This cysticercoid was also found in low prevalence of $0.03-0.5 \%$ in A. salina from Tegiz lake [19]. The author mentioned also findings of the adult tapeworm in avocets but saw scolices and strobila fragments of E. avoceti in juvenile flamingos as well.

The larval stage of two further members of the Flamingolepis genus was described in Artemia sp. from Camargue wetlands. Cysticercoids of both F caroli and F. flamingo were detected in a very low prevalence of $0.074 \%$ and only single cysticercoids were found in infected shrimps [20]. A survey on cysticercoids in Artemia parthenogenetica originating from the Odiel Marshes in Andalusia in Spain revealed the presence of 8 different species, amongst them Anomotaenia tringae and an Anomotaenia species with 26-30 rostellar hooks. Scolex structures of the latter species showed some similarities with $A$. microphallus an euryxenous cestode of waders. However, none of the descriptions of $A$. microphallus reported more than 24 rostellar hooks. Other species found in this study were $F$. liguloides, F. flamingo, C. podicipina, W. stellorae, E. avoceti and $G$. stammeri [21].

Further research on the role of brine shrimps as intermediate hosts of avian cestodes was done in saline lakes in Algeria [22], in the Western Mediterranean costs of Spain and France [23]. Extension of research work on A. salina and A. parthenogenetica in the Odiel Marshes in Spain showed the presence of 9 already known cestode larval stages and revealed a so far undescribed cysticercoid that was allocated to the genus Gynandrotaenia [24]. A further Artemia species occurring in the Odiel Marshes is the neozoon $A$. franciscana. This species originates from San Francisco Bay and Great Salt Lakes in North America and was introduced to Spain in the $1980^{\text {th }}$. Apart from cysticercoids of F. liguloides, F. flamingo, E. avoceti and $G$. stammeri A. franciscana was also infected with nematode larvae of the Acuariidae family. Redon et al. [25] studied parasite development stages of $A$. franciscana in the Great Salt Lake in Utah and found infections with four different cestodes $(C$. podicipina, H. californicus, Wardiumsp. and Fuhrmannolepis averini) along with larval stages of a nematode belonging to the Acuariidae family [26-30].

\section{Conclusion}

Artemia spp. in their inland saltwater habitats play an important role as food source for wader birds. Feeding on plankton, brine shrimps ingest also helminth eggs and had become intermediate hosts for avian cestodes. So far, cysticercoids of 16 different species of the Hymenolepididae, Dilepididae and Progynotaeniidae were found in Artemia spp.

\section{References}

1. Asem A, Rastegar PN, de los Rios EP (2010) The genus Artemia Leach, 1819 (Crustacea: Branchipoda) 1 true and false taxonomical descriptions. Lat A m J Aquat Res 38: 501-506.

2. Van Strappen G (1996) Introduction, biology and ecology of Artemia. In: Lavens P \& Sorgeloos P (Eds.), Manual on the production and use of live food for aquaculture. FAO, Italy, pp. 79-123.

3. Greaves PM (2012) An introduction to the branchipod crustaceans. Quekett J Microsc 41: 679-694.

4. Young RT (1952) The larva of Hymenolepis californicus in the brine shrimp (Artemia salina). J Washington Acad Sci 42(12): 385-388.

5. Gvozdev EV, Maksimova AP (1971) The Helminth fauna of the greater flamingo (Phoenicopterus roseus Pall) in Kazakhstan (in Russian). Trud Inst Zool AN Kaz SSR 31: 41-45.

6. Maksimova AP (1973) Branchiopods-intermediate hosts of cestodes of the family Hymenolepididae (in Russian). Parazitologiya 7: 349-351.

7. Maksimova AP (1976) A new cestode, Fimbriaroides tadornae sp and its development. In the intermediate host (in Russian). Parazitologiya 10: $16-24$.

8. Maksimova AP (1977) Branchiopods-intermediate hosts of the cestode Anomolepisa verini (Cestoda: Dilepididae). Parazitologiya 11: 77-79. 
9. Gvozdev EV \& Maksimova AP (1979) Morphology and life cycle of Gynandrotaenia stammeri (Cestoidea: Cyclophyllidea) parasite of the flamingo (in Russian). Parazitologiya 13: 56-60.

10. Gabrion C, Mac Donald G (1980) Artemia sp (Crustacea, Anostracea) as intermediate host of Eurycestus avoceti Clark, 1954 (Cestoda, Cyclophyllidea). Ann Parasitol Hum Comp 55(3): 327-331.

11. Panin VJ (1960) 0 the helminth fauna of the Lake Zaysan (in Russian). Trud Inst Zool AN Kaz SSR 12: 166-172.

12. Gvozdev EV (1964) Cestodes of huntable birds of southern Kazakhstan (in Russian). Trud Inst Zool AN Kaz SSR 22: 74-109.

13. Zatkanbaeva D (1968) Helminths of fish-eating birds of Kazahstan. Thesis Institute of Zoology of the Academy of Science of Kazakhstan, Asia, pp. 24.

14. Maksimova AP (1981) Morphology and life cycle of the cestode Confluaria podicipina (Cestoda: Hymenolepididae) (in Russian). Parazitologiya 15: 325-331.

15. Maksimova AP (1986) On the morphology and biology of the cestode Wardium stellorae (Cestoda, Hymenolepididae (in Russian) Parazitologiya 20: 487-491.

16. Maksimova AP (1987) On the morphology and life cycle of the cestode Wardium fusca (Cestoda, Hymenolepididae (in Russian). Parazitologiya 21: 157-159.

17. Maksimova AP (1988) A new cestode, Wardium gvozdevi sp. n. (Cestoda: Hymenolepididae), and its biology. Folia Parasitol 35: 217-222.

18. Maksimova AP (1990) Branchinella spinosa (Anocostra), an intermediate host of the cestodes of the genus Wardium (Cestoda: Hymenolepididae) (in Russian). Parazitologiya 24: 89-92.

19. Maksimova AP (1991) On the ecology and biology of Eurucestus avocet (Cestoda: Dilepididae). Parazitologiya 25: 73-76.

20. Robert F, Gabrion C (1991) Cestodes of Birds in Camarge. Importance of Artemia (Custacea, Anostraca) and meeting strategy between hosts and parasites (in French). Ann Parasitol Hum Comp 66(5): 226-235.

21. Georgiev BB, Sanchez MI, Green AJ, Nikolov PN, Vasilieva GP, et al. (2005)
Cestodes from Artemia parthenogenetica (Crustacea, Branchipoda) in the Odiel Marshes, Spain: a systematic survey of cysticercoids. Acta Parasitol 50(2): 105-117.

22. Amarouayache M, Derbal F, Kara MH (2009) The parasitism of Flamingolepis liguloides (Gervais, 1847) Cestoda, Hymenolepididae in Artemia salina (Crustacea, Branchiopoda) in two saline lakes in Algeria. Acta Parasitologica 54(4): 330-334.

23. Vasilieva GP, Redon S, Armat F, Nikolov PN, Sanchez MI, et al. (2009) Records of cysticercoids of Fimbriarioides tadornae (Maksimova, 1976) and Brachiopodataenia gvozdevi (Maksimova, 1988) (Cyclopyllidea, Hymenolepididae) from brine shrimps at the Mediterranean coasts of Spain and France, with a key to cestodes from Artemia spp from the Western Mediterranean. Acta Parasitol 54: 143-150.

24. Sanchez MI, Nikolov PN, Georgieva DD, Georgiev BB, Vasilieva GP, et al. (2013) High prevalence of cestodes in Artemia spp thoughg out the annual cycle: relationship with abundance of avian final hosts. Parasitol Res 112(5): 1913-1923.

25. Redon S, Berthelemy NJ, Mutafchiev Y, Amat Y, Georgiev BB, Vasilieva GP (2015) Helminth parasites of Artemia franciscana (Crustacea: Brachiopoda) in the Grat Salt Lake, Utah: first data from the native range of this invader of European wetlands. Folia Parasitol 62: 1-16.

26. Annonymous (2017) The list of wetlands of international importance.

27. Bondarenko S, Kontrimavicus V (2004a) On Brachiopodataenia n g, parasitic in gulls, and its type-species, B anaticapicirra $n$ sp (Cestoda: Hymenolepididae). Syst Parasitol 57: 119-133.

28. Bondarenko S, Kontrimavicus V (2004b) Life-cycles of cestodes of the genus Brachiopodataenia (Cestoda: Hymenolepididae) from gulls in Chukotka. Syst Parasitol 57: 191-199.

29. Georgiev BB, Angelov A, Vasilieva GP, Sanchev MI, Hortas F, et al. (2014) Larval helminths in the invasive American brine shrimp Artemia franciscana throughout its annual cycle. Acta Parasitol 59: 380-389.

30. Spasskij AA, Jurpalova NM, Kornjushin VV (1968) A new dilepidid genus Anomolepis n.g. (Cestoda, Cyclophyllidea). Vestnik Zool 2(5): 46-51.
Creative Commons Attribution 4.0

International License

For possible submissions Click Here
Submit Article

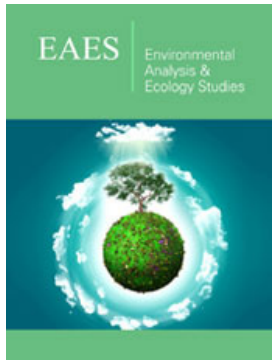

\section{Environmental Analysis \& Ecology Studies}

\section{Benefits of Publishing with us}

- High-level peer review and editorial services

- Freely accessible online immediately upon publication

- Authors retain the copyright to their work

- Licensing it under a Creative Commons license

- Visibility through different online platforms 